\title{
A Pesquisa Científica e o Interesse Público*
}

\author{
Simon Schwartzman \\ Diretor do American Institutes for Research para o Brasil (AIRBrasil)
}

Resumo

Esteartigo resumeas principaisconclusões de uma pesquisa queexaminou o relacionamento entre a pesquisa científica e tecnológica e o interesse público no Brasil, nas áreas de pesquisa agrícola eambiental, farmacêutica enas ciências sociais- pesqui sas sobretrabal ho eeducação. A tese principal éque, em países em desenvolvimento, o principal parceiro eusuário potencial dos conhecimentos gerados pela pesquisa não é o setor privado, mas o setor público. Esta parceria entre instituições de pesquisa e agências públicas requer novas formas de institucionalização tanto da pesquisa quanto das agências de política científica, de maneira tal que seja possível aumentar a utilidade social da pesquisa, preservando ao mesmo tempo os padrões de liberdade acadêmica equalidade que são essenciais em qual quer trabal ho denatureza científica etecnológica.

Palavras-Chave | CiênciaeEstado; CiênciaeSociedade; Sistemas delnovação; Instituições Científicas; Políticas deC iênciaeTecnologia

\begin{tabular}{l|l} 
Códigosjel & $0,03,038$
\end{tabular}

\footnotetext{
Este artigo resume as principais idéias e conclusões de um trabalho mais amplo sobre "Ciência, Tecnologia e Interesse Público", realizado ao longo de 2001 com a participação de Marilia Coutinho, Paulo dos Santos Rodrigues e Maria Helena de Magalhães Castro, abrangendo as áreas da pesquisa agrícola e ambiental, pesquisa de fármacos e pesquisa em educação e trabalho. Uma versão preliminar deste trabalho foi objeto de um seminário realizado na Academia Brasileira de Ciências em março de 2002, e se beneficiou dos comentários de Antônio Botelho, Carlos Augusto Grabois Gadelha, Márcio da Costa, Nadya Castro Araújo e Sérgio Paulino de Carvalho. Este trabalho contou com o apoio do Conselho Nacional de Desenvolvimento Científico e Tecnológico, e os autores agradecem o apoio recebido por parte de Evando de Paula Mirra e Silva e Alice de Paiva Abreu, que não têm nenhuma responsabilidade, pessoal ou institucional, pelos conceitos e interpretações apresentados aqui.
} 


\section{ABstract}

This essay summarizes the main conclusion of a research project that examined the relationships between science and technology and the public interest in Brazil, in the areas of agriculture, environment, pharmaceutical research and the social sciences- labor and education. The main proposition is that, in developing countries, the main potential partner and user of research-based knowledge is not the private, but the public sector. The partnership between research institutions and public agencies requires new ways of organizing both the research and the science policy institutions, in order to increase their social usefulness and to preserve the freedom and quality standards which are essential in any scientific and technological endeavor.

KeYWordS I Scienceand State; Scienceand Society; Innovation Systems; Scientific Institutions; Scienceand Technology Policies

JEL-CODES $\quad 0,03,038$

\section{Introdução}

N osúltimosanostem havido muita insistência, naliteratura especializada, sobrea necessidadedequeasinstituições depesquisa não fiquem isoladas, etratem de sevincular mais fortementeao setor produtivo, tornando-semais relevantese conseguindo, ao mesmo tempo, mais apoio erecursos. H ojejá não se fala tanto em sistemas de "Ciência e Tecnologia" ou "Pesquisa e D esenvolvimento", mas sim, cada vez mais, em "Sistemas de Inovação". A suposição é que, nos países mais desenvolvidos, a integração entreasinstituições científicas etecnológicaseo sistema produtivo se dá de forma muito mais completa e natural do que nos países em desenvolvimento, onde o setor científico etecnológico tenderia a ficar mais isolado. I sto deveria ser compensado por um esforço dirigido esistemático para aproximar a pesquisa do setor produtivo, através de diferentes tipos de incentivos financeiros e inovações institucionais. Este artigo pretende mostrar que, ainda quea vinculação entre a pesquisa científica eo setor produtivo seja de grandeimportância, o principal parceiro da pesquisa científica em países com as características do Brasil é o setor público. Esta parceria já existe na prática, mas suas implicações e conseqüências mais amplas ainda não são tomadas em conta 
nasformas deorganização das instituições de pesquisa científica, nem na maneira em queas instituições públicas deciência etecnologia se relacionam a elas.

\section{O mundo da ciência e o mundo dos interesses}

Tudo que se possa fazer para aproximar a pesquisa do setor produtivo será muito bem-vindo. A dificuldadeéque, com a globalização crescenteda economia, as atividades de pesquisa edesenvolvimento das grandes corporaçõestendem ase localizar em alguns lugares privilegiados nos países centrais, enquanto que as pequenasempresastendem a operar pelacompra de pacotestecnológicosfechados. Por isto, a demanda por investimentos em pesquisa e desenvolvimento por parte deempresas privadas em países menos desenvolvidos não é grande, e será sempre insuficiente para absorver o potencial de pesquisa dos centros acadêmicos que procuram trabal har na fronteira do conhecimento de suas respectivasáreas.

N o entanto, épossível argumentar que o grande comprador eusuário da pesquisa científica etecnológica não énecessariamenteo setor produtivo privado, maso setor público. São os governos que fazem guerras, produzem armamentos, respondem a emergências e catástrofes, cuidam da saúde pública, da educação, da ordem pública, do meio ambiente, do abastecimento deágua, saneamento, energia, transportes públicos, comunicações, fazem mapeamentos e prevêem 0 tempo. Todas estas atividades requerem pesquisas e estudos permanentes, e grandes investimentos. Elas podem ser implementadas tanto por instituições governamentais como não-governamentais, mas o setor público é sempre responsável pela sua regulação e acompanhamento, além de ser o principal financiador ecomprador. ${ }^{1}$

Q uando existe uma interação bem estabel ecida entre as instituições de pesquisa e o setor público, verificam-se importantes benefícios para ambos. Com apoio científico etecnológico mais consistente, as políticas públicas podem se tornar mais eficientes e eficazes; com uma vinculação mais próxima a atividades de interesse público, o setor de pesquisa se fortalece, obtendo mais reconhecimento, legitimidade e recursos, atraindo maistalentose competência.

1 Ver, para uma visão abrangente da evolução e transformações da política científica desde a ll Guerra, Elzinga e Jamison (1995). 
Se há interesse de parte a parte, seria de se esperar que este casamento de conveniênciamútua pudessesempresedar sem maiores dificuldades. N o entanto, o estabelecimento deformas adequadas de cooperação eapoio mútuo entre os pesquisadores e os responsáveis pelos governos e pela administração pública não éalgo quese possa considerar como óbvio enatural. Ao contrário, a história da ciência etecnologia modernas mostra queesta relação tem sido muitas vezes difícil, ainda que a proximidade tenha sempre preponderado, sobretudo nos países da Europa ocidental enos Estados Unidos, que são as principais bases da ciência e da tecnologia mundiais. Estas dificuldades podem ser de duas ordens. A primeira, mais familiar para quem vive e trabalha na América Latina, é 0 lugar relativamente secundário que ocupam os cientistas e pesquisadores em suas sociedades, sem maior participação nos centros de decisão, e atuando sobretudo como lobistas na defesa de suas visões de mundo e interesses profissionais. A segunda, no extremo oposto, são as tentativas de colocar os pesquisadores e suas instituições ao reboque de políticas e ideologias governamentais rígidas, sufocando, desta maneira, a liberdade de pesquisa ede expressão dos cientistas e pesqui sadores, como ocorreu nos regimes totalitários daRússia eAlemanha. ${ }^{2}$

A primeira dificuldade sempre dominou a visão da comunidade científica brasileira ${ }^{3}$ a respeito da própria experiência. Existe uma longa tradição de queixa do setor em relação aos governos pela pouca prioridade dada à pesquisa, pela limitação e instabilidade dos recursos, e pelo pouco ou nenhum uso que éfeito dos conhecimentos e contribuições dos cientistas. A esta real idade os pesquisadores contrapõem uma outra visão sobre o que seria uma sociedade cientificamente avançadae racional, onde a tecnologia nacional al avancaria a indústria ea agricultura, a saúde pública seria atendida, os direitos humanos e sociais seriam preservados, os problemas de degradação ambiental

\footnotetext{
No caso da União Soviética, as ciências exatas e as tecnologias floresceram, enquanto que as ciências sociais e biologia, afetadas mais de perto por questões ideológicas, não prosperaram (Graham, 1998, Joravsky, 1970). Na Alemanha, o desenvolvimento científico sob o Nazismo parece ter sido maior do que normalmente se presume, dada a politização extrema a que as universidades e centros de pesquisa daquele país foram submetidos. Uma reavaliação da ciência alemã no período nazista vem sendo feita por uma Comissão Nacional encarregada de conhecer mais em profundidade a história da Sociedade Kaiser Wilhelm em seu relacionamento com o regime nazista. Ver a respeito http://www.mpiwg-berlin.mpg.de/kwg/engl.htm

3 A expressão "comunidade científica" se refere, em primeira instância, ao conjunto de cientistas e pesquisadores do País,sem nada presumir a respeito de seu grau de organização e integração como comunidade efetiva. No entanto, não há dúvida que ela tem também uma realidade sociológica, expressa através de instituições próprias, como a Academia Brasileira de Ciências, a Sociedade Brasileira para o Progresso da Ciência e um grande número de organizações científicas específicas, que se comunicam entre si. Ver a respeito Schwartzman, 2001
} 
seriam controlados, eas riquezas naturais seriam bem exploradas e colocadas a serviço da comunidade.

Esta maneira de entender a ciência como a portadora do progresso, da racionalidade e do futuro faz parte do contexto social e político em que a ciência se desenvolveu no mundo moderno desdeo R enascimento, dentro de um processo muito mais amplo de racionalização e desenvolvimento das economias capitalistas, e tem sido retomada, nos últimos anos, pelas novas teorias do Capital H umano e da Sociedade do Conhecimento, que seria a característica central da economia globalizada de nossos dias. A ingenuidade com quea comunidade acadêmica abraça esta visão triunfante de seu próprio papel não consisteem acreditar no grande potencial da ciência eda tecnologia, que é inegável em termos gerais; mas sim em deixar de considerar a complexidade, contradições e armadilhas que existem na prática da implementação de políticas científicas, tecnológicas e educacionais em condições específicas, que acabam produzindo resultados inesperados. ${ }^{4}$

Em outro texto, tive a oportunidade de examinar como, desde os tempos coloniais, sucessivas gerações de médicos, engenheiros, advogados, sociólogos e economistas trataram de convencer a sociedade brasileira da contribuição inestimável que eles poderiam dar, se obtivessem 0 reconhecimento, a autoridade e o poder de decisão a que se julgavam com direito, pelos seus dons intelectuais e culturais (Schwartzman, 1997). N a perspectiva do tempo, é fácil ver como estas pretensões eram desmedidas, dadas as próprias limitações das ciências e dos conhecimentos de que estas elites dispunham; e como as grandes ambições de transformar e reformar a sociedade evoluíram para a defesa dos interesses privados das corporações profissionais eacadêmicas, sem perder, no entanto, o discurso revolucionário e messiânico dos primeiros anos. ${ }^{5}$ Processo semelhante ocorre com a comunidade científica e acadêmica, na medida em que crescem e se desenvolvem suas organizações corporativas. ${ }^{6}$

\footnotetext{
4 O contraste entre esta visão ingênua (também denominada de "acrítica" ou "tecnocrática") e a visão mais ponderada e crítica (também denominada "reflexiva") sobre o papel da ciência e tecnologia na sociedade é muito bem apresentado e discutido por Edge (1995). Para uma reflexão mais antiga, ver Schwartzman (1981a).

5 Os esforços patéticos das elites profissionais brasileiras em garantir seus monopólios são descritos com erudição e ironia em Coelho (1999).

6 Ver, entre outros, Schwartzman (1994a); Botelho e Schwartzman (1997); Schwartzman e Balbachevsky (1996).
} 
Esta visão crítica não deveser entendida como uma tomada de posição no sentido oposto, ou seja, como uma negação da grandeimportância potencial das profissões e da ciência e tecnologia para o País. Ao contrário, o que se busca é entender melhor quais os limitese asverdaderas possibilidades destacontribuição, para que ela setornemais efetiva e relevante.

Se, por um lado, existe uma forte tendência, nos meios profissionais e acadêmicos, desupervalorizar seu próprio papel, existepor outro uma dificuldade bastantecomum em perceber quando o setor público se movee seorganiza para proporcionar recursos e aumentar o papel e a presença do setor de ciência e tecnologia no País. Seria possível dizer que estes momentos são relativamente raros em nossa história, mas não deixaram de existir, com a criação de institutos biológicos eagrícolas eascampanhas sanitáriasna entrada do século XX, a criação da Universidade de São Paulo nos anos 1930, a mobilização para o esforço de guerra naSegunda Guerra M undial, a criação do CN Pq e CBPF nos anos 1950, a reformulação do sistema de ciência e tecnologia e de pós-graduação, a criação da FIN EP edaEM BRAPA nos anos 1970, ea criação dos fundos setoriais nos anos mais recentes. Além destes eventos mais óbvios, existeuma série de iniciativase instituições que, por diferentes razões, nem sempresão percebidos como fazendo parte do sistema de ciência e tecnologia, apesar de seu porte e importância: instituições como o Instituto $\mathrm{N}$ acional de Tecnologia, o Instituto de Pesquisas Tecnológicas deSão Paulo, o IBGE, o IPEA, o Instituto Tecnológico daAeronáutica, o Instituto M ilitar de Engenharia; e iniciativas como o programa nuclear, 0 programa espacial e os programas mais recentes de produção de vacinas e medicamentos. Assim, o setor deCiênciaeTecnologia conta com órgãose políticas governamentaisininterruptas desde pelo menos os meados do século, financiando pesquisas, proporcionando bolsas de estudo, criando e mantendo instituições, estabelecendo fundos e linhas de financiamento. Podese falar de inadequação das políticas ede fortes oscilações deorçamento, masnão de sua ausência.

Para entender em maior profundidadecomo se dáo relacionamento entre a comunidade científica e o setor público, examinamos al gumas áreas em que existem linhas de atividade deforteconteúdo tecnológico por parte do Governo Federal. Estas áreas foram a da pesquisa agropecuária emeio ambiente, ${ }^{7}$ aonde

7 Sob a responsabilidade de Marília Coutinho. 
existe uma grande tradição de trabalho aplicado eestá surgindo um novo setor, o de pesquisas ambientais, onde as questões de cooperação internacional, propriedade intelectual e mobilização da sociedade convergem de forma especialmenteaguda, sem que existam ainda políticas governamentais definidas a respeito; a da produção demedicamentos, eparticularmenteo Far-M anguinhos, da Fundação 0 swal do C ruz; ${ }^{8}$ onde está se desenvolvendo todo um trabalho de natureza científica e industrial em resposta a uma política definida de desenvolvimento de competência para a substituição de importações; e em duas áreas de pesquisa social, trabalho e educação, ${ }^{9}$ que se caracterizam pela existência de recursos públicossignificativos, seja através do Fundo deAssistência ao Trabal hador $^{10}$ para a primeira, seja através dos novos recursos nacionais e internacionais que permitiram a transformação do antigo Instituto $\mathrm{N}$ acional deEstudose PesquisasEducacionais (IN EP), "1 hoje responsável pela produção das estatísticas educacionais edeum amplo programa deavaliação dedesempenho da educação em todos os seus níveis.

A existência de recursos públicos, novas frontei ras tecnológicas efortes interesses sociais nestas áreas faz com que a atividade de pesquisa se organize de forma muito distinta da que ocorre usualmente na ciência acadêmica mais convencional. A pesquisa agropecuária sempresedesenvolveu no Brasil deforma relativamenteisolada, o quese acentuou com a criação daEmbrapa. A pesquisa ambiental, por outro lado, tem aplicaçõesmenos definidas, pela própria ausência depolíticas públicas para o setor, maséobjeto degrandemobilização deinteresses nacionaiseinternacionais, esecaracteriza por um al to envolvimento dos próprios pesquisadores em controvérsias de política pública. N ovas tecnologias, especial mente aquelas associadas ao zoneamento ambiental através desistemas de informação geográfica e elaboração de modelos complexos, vem exigindo

\footnotetext{
8 Sob a responsabilidade de Paulo dos Santos Rodrigues.

9 Sob a responsabilidade de Maria Helena Magalhães Castro.

${ }^{10}$ O Fundo de Assistência ao Trabalhador foi instituído em 1990, para administrar os recursos dos antigos programas de integração social - PIS - e de Formação do Patrimônio do Servidor Público - PASEP, que deveriam, pela constituição de 1988, serem destinados ao custeio do Programa do Seguro-Desemprego, do Abono Salarial e, pelo menos 40\%, ao financiamento de Programas de Desenvolvimento Econômico, a cargo do Banco Nacional de Desenvolvimento Econômico e Social - BNDES. Uma parte importante dos recursos é utilizada para financiar o Programa Nacional de Qualificação do Trabalhador - PLANFOR, entendida como parte do programa do Seguro-Desemprego. As atividades de pesquisa são financiadas, geralmente, de forma acessória e este programa. Ver a respeito Todeschini (2002).

${ }^{11}$ O INEP foi criado nos anos 1930, e passou por vários períodos de ascensão e crise, até o seu apogeu recente, na gestão de Maria Helena Guimarães Castro. Ver, para a história mais remota, Mariani (1982).
} 
novas competências, trabalho interdisciplinar euma nova escala de recursos. A pesquisa de fármacos se desenvolve dentro de uma lógica industrial que requer a integração de toda a cadeia de estudos e pesquisa que vai da identificação de princípios ativos à elaboração dos fármacos e sua testagem, envolvendo supridores eprestadores deserviços externos equestões de propriedadeintelectual queainda são pouco usuaisnosmeioscientíficos brasileiros. $\mathrm{N}$ aárea das pesquisas do trabalho, a existência dos recursos do FAT gerou toda uma rede de pesquisadores cujas fontes de financiamento emecanismos deavaliação não são mais, somente, os da pesquisa acadêmica tradicional, mastambém os dasagendas às vezes contraditórias dos controladores do Fundo. Ao mesmo tempo, a disponibilidade de grandes bases de dados, mantidos pelo IBGE, Fundação SEADE e M inistério do Trabalho, abriu espaço para novas especialidades e competências, mais típicas de economistas e demógrafos do que das ciências sociais maistradicionais. $\mathrm{N}$ a área da educação, 0 desenvolvimento das estatísticas educacionais e dos novos sistemas de avaliação também abriu espaço para uma nova geração de estudos e pesquisas que, tal como na área do trabalho, requer competências maistípicas deeconomistas, demógrafose estatísticos do queas mais encontradas na área tradicional de pedagogos, sociólogose educadores.

Tanto em um como em outro caso, as atividades de pesquisa não se organizam como uma área de atividade constituída de forma explícita, com recursos e procedimentos claros de contratação e acompanhamento de projetos, mas ocorrem na prática, pela utilização de recursos que podem ser muito significativos para os pesquisadores, mas insignificantes em relação às atividades centrais dos $\mathrm{M}$ inistérios a que servem. ${ }^{12}$ Em cada uma destas iniciativas, eem graus diferentes em cada caso, existem semprealguns segmentos da comunidade científica que participam, enquanto quemuitosoutrosolham com desconfiança o fato de se tratarem de iniciativas governamentais, com a participação ativa de $M$ inistérios e instituições que nem sempre trabalham de forma coordenada com as agências usuais quelidam com ciência e tecnologia no País, nas quaisa presença e a voz da comunidade científica está mais institucionalizada.

$\mathrm{N}$ ão setrata, somente, de uma atitude de preconceito e desconfiança. D e maneira geral, a cultura e as formas de trabalho típicas da área científica são

\footnotetext{
${ }^{12}$ É uma situação semelhante à do antigo Fundo de Tecnologia do BNDES, que mais tarde deu origem ao Fundo Nacional de Desenvolvimento Científico e Tecnológico e à FINEP.
} 
muito diferentes das que predominam nas burocracias públicas enas empresas privadas. Ainda que generalizações sejam sempre limitadas por importantes exceções, é possível caracterizar a cultura organizacional da área acadêmica e científica pela grandeautonomia eliberdade de ação dos pesquisadores-seniores, pela flexibilidade nosmecanismos de controledas atividades quotidianas, e pela transparência e publicidade em relação aos resultados obtidos. Em contraste, as organizações burocráticas eempresariais tendem a ser maisfechadas, eisto pode levar tanto à perda da independência do pesquisador ante seus chefes e financiadores, quanto ao seu extremo oposto, mais típico talvez do serviço público, que é a falta absoluta de critérios externos de aval iação e padrões de qual idade. Estas diferenças de estilo e cultura organizacional parecem ser mais importantes, para explicar as tensões e dificuldades de relacionamento que ocorrem entre a comunidade científica e o setor público, do que as eventuais diferençasideológicas que possam existir entre representantes dos dois setores. ${ }^{13}$

\section{Ciência básica e ciência aplicada}

A questão da efetividade da pesquisa científica e tecnológica tem sido muitas vezes colocada em termos de uma oposição queexistiria entre a pesquisa como atividade acadêmica, pura e desinteressada de suas possíveis aplicações, e a pesquisa como orientada e voltada para determinados fins.

O spossíveis vínculos e tensões entre a ciência básica e a ciência aplicada têm sido objeto de constante preocupação. Por exemplo, Eduardo Krieger e Fernando Galembeck, na conclusão de um amplo estudo sobre a pesquisa brasileira realizado em meados dos anos 1990, observam que existe um grande distanciamento entre o mundo da pesquisa e o mundo empresarial, que seria o das aplicações, ecaracterizam desta forma o ambiente científico brasileiro:

i) a perenidade de um estéril conflito de interesses entre os defensores da "pesquisa básica" e da "pesquisa aplicada”, em que seignora a extrema

\footnotetext{
${ }^{13}$ Isto ajuda a entender o fato de as reformas dos anos 1970, de fortalecimento das instituições de pesquisa e pós-graduação, terem contado com grande aprovação do meio científico, apesar da polarização política e ideológica que havia naqueles anos entre o governo militar e lideranças científicas e universitárias significativas.
} 
interdependência entre ambas e a necessi dade de atividade vigorosa em ambas, em qualquer sistema de desenvolvimento científico etecnológico que aspirea al guma perenidade;

ii) a falta de vínculos constantemente renovados entre pesquisadores universitários e profissionais de empresas; por exemplo, sociedades científicas e sociedades profissionais são corpos distintos, que não se interpenetram nem interagem, à exceção dealguns casos notáveis. É um fato recente e positivo a existência de algumas entidades, como as associações brasileiras de cerâmica ( $A B C$ ) e de polímeros (ABPol) que congregam pesquisadores e profissionais industriais de forma eficaz e produtiva;

iii) a existência de muitos argumentos de rejeição mútua, entre profissionais deempresas epesquisadoresuniversitários. Estesargumentos são tanto mais chocantes quando se reconhece que, no Brasil, todos esses profissionais têm as mesmas origens. (K rieger eG alembeck, 1996.)

Vendo esta descrição, o leitor poderá ficar com a impressão de que os cientistas brasileiros vivem em suas torres demarfim, financiados por agências que só se preocupam com a qualidade científica dos trabalhos, sem atentar para sua eventual relevância ou utilidade. $\mathrm{N}$ ada mais incorreto. D esde seus primórdios, a maior parte dos recursos públicos para a pesquisa científica no Brasil sempre se orientou para atividades de interesse prático, nos jardins de aclimatação e museus geológicos do Império; nas instituições de pesquisa agropecuária e institutos de combate às doenças tropicais da virada do século; na criação do CN Pq e do Centro Brasileiro de Pesquisas Físicas nos anos 1950; ou na atualidade, quando $66 \%$ dos recursos dos programas de pesquisa do País são consumidos pelas áreas de tecnologia industrial e programas militares de grande porte (ver Tabela 1$).{ }^{14}$

\footnotetext{
${ }^{14}$ A organização dos dispêndios do governo brasileiro em programas é uma característica central do sistema gerencial que o Governo Federal buscou implantar através do Plano Plurianual Avança Brasil - 2000/2003. O objetivo, extremamente louvável, é permitir que se possa acompanhar os gastos públicos em termos de objetivos explícitos, que possam ser então avaliados. No entanto, faltam informações mais precisas sobre o que são dispêndios estimados e dispêndios efetivamente realizados, sobre as agências responsáveis pela execução dos programas, e os gastos de pessoal estão listados em separado. Por estas razões, estes dados devem ser tratados com cautela. Além do documento que descreve o Plano Plurianual, o Ministério do Planejamento e Orçamento disponibiliza os dados relativos aos dispêndios de cada programa no ano 2000. As informações de dispêndio se encontram em Brasil, Ministério do Planejamento, 2001.
} 
TABELA ।

Despesas da União em Ciência e Tecnologia, 2000

Grupos de Programas

\begin{tabular}{lc}
\hline Total & $R \$ 2.804 .665 .950$ \\
\hline Formação de Recursos Humanos & 908.137 .248 \\
Pesquisa Social * & 523.400 .341 \\
Tecnologia Industrial & 414.524 .627 \\
Programas Militares e de grande porte & 328.363 .482 \\
Tecnologias da Informação & 211.918 .013 \\
Recursos Naturais e Meio Ambiente & 114.887 .727 \\
Saúde & 112.213 .691 \\
Pesquisa Básica & 106.664 .990 \\
Pesquisa Agropecuária & 55.285 .104 \\
Outros & 29.270 .727 \\
\hline
\end{tabular}

* Inclui 455 milhões de reais para o Censo Demográfico do ano 2000.

Fonte: elaborado a partir de dados do Ministério do Planejamento. Despesas por programa, exercício de 2000.

Segundo estes dados, um terço dos recursos brasileiros para ciência e tecnologia teriam sido gastosem programas de formação de pós-graduação eem bolsas de estudo (programas de capacitação). A pesquisa social aparece como segundo item por causa do Censo do ano 2000 - não fosseisto, ela ficaria reduzida a cerca de 74 milhões, concentrados nos gastos do INEP e do IBGE. ${ }^{15}$ O s programas militares, como o aeroespacial, nuclear e naval, ainda consomem uma proporção grande dos recursos; ea maior parte dos gastos em tecnologia da informação seria para a manutenção do serviço de informática para o setor público. 0 item de "pesquisa básica", descrito pelo M inistério como "expansão econsolidação do conhecimento científico etecnológico", éo de queo M inistério daCiência eTecnologia efetivamentedispõe para atender aosprojetos de pesquisa oriundos da comunidade científica. D estes, cerca de metade, 50 milhões de reais, ou 1,7\% do total, é distribuído pelo programa de auxílio à pesquisa pelo CN Pq. A distribuição destes recursos por grandesáreas de conhecimento pode ser vista naTabela 2. Estes dados confirmam, mesmo neste âmbito restrito, 0 predomínio das áreas aplicadas deengenharia esaúde, ea presença relativamente reduzida das ciênciassociais ehumanas.

\footnotetext{
${ }^{15}$ Programa de Estatísticas e Avaliações Educacionais (INEP): R\$ 36.240.384; programa de Informações Estatísticas e Geográficas (IBGE): 17.335.262; programa de Informação e Conhecimento em Políticas Públicas (IPEA): 13.086.614. Estes dados não incluem o pagamento de pessoal regular.
} 
Valor dos auxílios para pesquisa em 1999, agrupados por grandes áreas

\begin{tabular}{lcc}
\hline & Real & $\%$ \\
Engenharias & $12.011 .585,60$ & 21,85 \\
Ciências da Saúde & $9.855 .063,60$ & 17,93 \\
Exatas & $8.142 .545,50$ & 14,81 \\
Agropecuária & $7.635 .108,10$ & 13,89 \\
Biológicas & $5.337 .644,60$ & 9,71 \\
Meio ambiente & $3.740 .736,70$ & 6,80 \\
Ciências Sociais Aplicadas & $3.573 .147,00$ & 6,50 \\
Ciências Sociais Básicas & $2.638 .427,10$ & 4,80 \\
Humanidades & $2.041 .381,90$ & 3,71 \\
\hline Total & $54.975 .640,10$ & 100 \\
\hline
\end{tabular}

Fonte: agrupados a partir de dados do CNPq.

Se os recursos financeiros para os programas de pesquisa se concentram nas áreas aplicadas, os recursos humanos se concentram nas instituições acadêmicas. D os 908 milhões de reais gastosna formação de recursos humanos no ano 2000, 509 milhões foram para os programas de "desenvolvimento do ensino de pós-graduação" concentrados nas universidades públicas, e 400 milhões em "capacitação de recursos humanos para a pesqui sa", ou seja, bolsas de estudo. O sdados conhecidos so bre os pesquisad ores brasi lei ros confirmam que, dos cerca de 30 mil doutores listados no diretório dos grupos de pesquisa do Brasil do CN Pq, mais de 90\% estão em instituições universitárias (Tabela 3). A mesma concentração ocorre quando olhamos para os pesquisadores como um todo, estimados em cerca de 50 mil. D as dez maiores instituições em número de pesquisadores, nove são universidades federais ou do sistema paulista, com a EM BRAPA ocupand o $06^{\circ}$ lugar, com 1.500 pesquisadores (a primeira éa U SP, com pouco mais de cinco mil). ${ }^{16}$ A segunda instituição não universitária, em tamanho, é a Fundação Instituto 0 swaldo $\mathrm{C}$ ruz, em $12^{\circ}$ lugar com 855 pesquisadores; vem a seguir a C omissão $\mathrm{N}$ acional de Energia N uclear, em $22^{\circ}$ lugar, com 589.

\footnotetext{
${ }^{16}$ Dados do diretório de grupos de pesquisa no Brasil, versão 4.1, http://www.cnpq.br/plataformalattes/dgp/versao4/ plano_tabular/index.html
} 
TABELA 3

Brasil, Número de pessoas em P\&D, por Setor de Execução e Campo da Atividade de P\&D, 1999

\begin{tabular}{|c|c|c|c|c|}
\hline & Total & Pesquisadores & $\begin{array}{l}\text { Pessoal Técnico } \\
\text { ou Equivalente }\end{array}$ & $\begin{array}{r}\text { Outro Pessoal } \\
\text { de Suporte }\end{array}$ \\
\hline Total(1) & 78.565 & 55.103 & 21.914 & 1.548 \\
\hline Setor Empresarial & 13.131 & 6.364 & 5.219 & 1.548 \\
\hline Governo & 9.772 & 5.926 & 3.846 & \\
\hline Ciências Naturais & 2.807 & 1.748 & 1.059 & \\
\hline Engenharia e Tecnologia & 1.642 & 982 & 660 & \\
\hline Ciências da Saúde & 1.655 & 868 & 787 & \\
\hline Ciências Agrárias & 2.840 & 1.714 & 1.126 & \\
\hline Ciências Sociais & 737 & 549 & 188 & \\
\hline Humanidades & 91 & 65 & 26 & \\
\hline Ensino Superior & 55.496 & 42.706 & 12.790 & \\
\hline Ciências Naturais & 14.689 & 10938 & 3.751 & \\
\hline Engenharia e Tecnologia & 8.825 & 6.936 & 1.889 & \\
\hline Ciências da Saúde & 12.225 & 8.730 & 3.495 & \\
\hline Ciências Agrárias & 6.184 & 4.030 & 2.154 & \\
\hline Ciências Sociais & 8374 & 7363 & 1.011 & \\
\hline Humanidades & 5.199 & 4.709 & 490 & \\
\hline Setor Privado sem Fins Lucrativos & 151 & 107 & 44 & \\
\hline Ciências Naturais & 11 & 4 & 7 & \\
\hline Ciências da Saúde & 12 & 8 & 4 & \\
\hline Ciências Sociais & 83 & 74 & 9 & \\
\hline Humanidades & 45 & 21 & 24 & \\
\hline
\end{tabular}

Fontes: Dados Brutos: Associação Nacional de Pesquisa, Desenvolvimento e Engenharia das Empresas Inovadoras (Anpei), para o setor empresarial; Conselho Nacional de Desenvolvimento Científico e Tecnológico (CNPq) - Diretório dos Grupos de Pesquisa, para os demais setores.

Elaboração: Coordenação de Estatísticas e Indicadores - Ministério da Ciência e Tecnologia.

Notas: As informações para o setor empresarial referem-se a 1999.

(1) Total inclui "Outro Pessoal de Suporte" no setor empresarial apenas, pois a estimativa desse contingente não está disponível para os demais setores.

Nota Específica Atualizada em 10/04/2002.

Fonte: http://www.mct.gov.br/estat

Estes dados mostram como os recursos humanos para a pesquisa se concentram em instituições acadêmicas e em uns poucos institutos públicos, restando pouco ou quasenada para o setor privado. Isto não significa, no entanto, queo conteúdo das pesquisas destas instituições seja também acadêmico. Estudos realizados no Brasil desde os anos 1980 mostram que só uma parte menor da pesquisa universitária tem as característicasusualmente associadasà pesquisa básica, ou seja, orientada para ostemas centrais de disciplinas como afísica, a biologia ou a química (Schwartzman, 1985). G rande parte das pesquisas que se fazem nas universidades, assim como nosinstitutos de pesquisa governamentais, são orientadas 
paratemas práticos, como as engenharias, as ciências da saúdeea educação. M as elas sedesenvolvem nosmoldesinstitucionaise organizacionais da pesquisa acadêmica ou do serviço público, esó raramente conduzem a aplicações efetivas.

São estesmoldesinstitucionaise organizacionais, mais do queo conteúdo ou a natureza das pesquisas, que fazem a diferença entre o que comumente se denomina de "pesquisa básica" ou "aplicada". Astentativas de definir em termos lógicos ou epistemológicos o que é a pesquisa básica ou a pesquisa aplicada normalmente fracassam, e não caberia voltar a esta questão aqui. O s cientistas, desde sempre, justificam suas verbas pela convicção, que procuram difundir, de queseu trabalho é sempreútil eimportante, eneste sentido sempre aplicado, ou pelo menosaplicável, ainda que de formaindireta ea longo prazo. 0 quemuitas vezesnão sepercebeéque, independentementedas intenções, a transformação de conhecimentos "básicos" ou "aplicados" em resultados efetivos dependedearranjos institucionais que geralmente não existem nos ambientes universitários e quase universitários em que as pesquisas se realizam e, em países pouco desenvolvidos tecnologicamente, tampouco fora deles.

\section{Os novos conceitos sobre a natureza e a organização da atividade científica}

D ois conceitos marcam o entendimento atual a respeito da natureza e a organização daatividadecientíficaetecnológica, o denão-linearidadeeo deinovação.

A noção de que as atividades de pesquisa e desenvolvimento obedecem a uma seqüência linear, que vai da pesquisa básica à pesquisa aplicada, desta ao desenvolvimento tecnológico, e deste, finalmente, ao produto de uso prático, não éa melhor descrição do que ocorreno mundo real. A literatura especializada, a partir sobretudo da experiência do Japão, sugerea existência de uma "seqüência invertida", que tem início com atividades de inovação de produtos, gerando competência para a criação de inovações mais complexas, e culminando no desenvolvimento depesquisa experimental ebásica (Branscomb eK odama, 1993). O utros autores argumentam que o que predomina são processos não-lineares, em que as atividades de pesquisa básica, experimental e o desenvolvimento de produtos se dão de forma simultânea e imprevisível, em complexos científico- 
tecnológicosqueincluem todas as etapas relevantes da cadeia de geração-produção de conhecimentose produtos. ${ }^{17}$

O tema dasnovas características da ciência etecnologiano mundo atual foi objeto de um livro de 1994, TheN ew Production of Knowledge (Gibbons, Trow, Scott et al., 1994), que procura contrastar o que teria sido o modo antigo de produção de conhecimentos, baseado nas estruturas acadêmicas e na separação formal das disciplinas - denominado de "modo 1" - e a realidade de hoje, que rompe as fronteiras entre o público e o privado, a pesquisa básica e a pesquisa aplicada, e outras características que seriam típicas do "modo 2":

Modos de produção de conhecimentos científicos

\begin{tabular}{ll}
\hline $\begin{array}{l}\text { Modo } 1 \text { ( linear) } \\
\begin{array}{l}\text { O conhecimento básico é produzido antes e } \\
\text { independentemente de aplicações }\end{array}\end{array}$ & $\begin{array}{l}\text { Modo } 2 \text { (não-linear) } \\
\text { aplicações }\end{array}$ \\
$\begin{array}{l}\text { Organização da pesquisa de forma disciplinar } \\
\text { Organizações de pesquisa homogêneas }\end{array}$ & $\begin{array}{l}\text { Transdisciplinaridade } \\
\text { Compromisso estrito com o conhecimento: os } \\
\text { pesquisadores não se sentem responsáveis pelas } \\
\text { possíveis implicações práticas de seus trabalhos }\end{array}$ \\
\hline
\end{tabular}

Fonte: Gibbons, Trow, Scott et al. 1994.

M uitosautores comentaram que, na realidade, a atividadecientífica sempre teve muitas das características do "modo 2", que não seria, portanto, uma novidade. Por exemplo, Steve Fuller observa que:

For while it is true that philosophers of science from the positivists to Kuhn have generally portrayed the natural sciences as self-contained epistemic communities on the model of Mode 1, the sciences have traditionally encountered resistance for their tendency to destabilize the arts-based power structures of the universities-mainly by forming makeshift alliances with the state and industry, often in foreign countries. Indeed, such fecund interdisciplinary research programmes as molecular biology

\footnotetext{
${ }^{17}$ Por exemplo, David (1997).
} 
and operations research have resulted from these alliances. But these developments all took place long before M ode 2 is said to have emerged. What, then, is new about M ode 2?" (Fuller, 1995).

A novidade, dizFuller com muita propriedade, não éa penetração daciência e tecnologia no mundo da indústria, mas a penetração do modo industrial na produção de conhecimento. $\mathrm{N}$ ão se trata tanto de uma transformação nas metodologiaseprocedimentostécnicosdaatividadedepesquisa, como, sobretudo, deumatransformação nacultura, valoreseinstituições dentro das quaisa atividade científica etecnológica se desenvolve.

0 "modo 1" corresponde a um sistema de valores eatitudes que étípico do establishment acadêmico, quefoi caracterizado pelo "tipo ideal" desenvolvido por Robert K. M erton. Entre outras, estas normas e valores incluiriam a propriedade compartida ("comunista", no dizer deM erton) dos conhecimentos produzidos; o ceticismo, como princípio sistemático de dúvida e exigência de rigor; e o desinteresse do cientista em relação aos eventuais ganhos monetários derivados da aplicação de seus conhecimentos- o prestígio eoslauréisacadêmicos seriam gratificações mais do que suficientes (M erton, 1973). U ma outra versão desta mesma idéia foi elaborada por J oseph Ben-D avid, que procurou mostrar como naEuropa ocidental, a partir do R enascimento, se desenvolveu um papel social para o cientista, queeraalimentado pelos valores do racionalismo edaquilo que ele denominou de "ideologia cientística" (Ben-D avid, 1971). M ais recentemente, Bruno Latour procurou mostrar que este sistema normativo, que pretende colocar os pesquisadores como que entre parênteses, é uma característica central da visão demundo moderna, que quer acreditar eampliar cada vez mais o poder do conhecimento e das ciências, de forma dissociada de seus condicionantes eimplicações mais gerais (Latour, 1993).

D izer que o modelo mertoniano deorganização da atividadecientífica está equivocado, ou superado, por não corresponder à evidência empírica sobre as formas em que a atividade científica se dá, énão entender o sentido mais amplo de um "tipo ideal" nas ciências sociais. ${ }^{18}$ Conhecimentos de tipo científico e

\footnotetext{
${ }^{18}$ É um equívoco semelhante ao dos que afirmam que os conceitos de Max Weber sobre a burocracia estariam superados, pela inexistência empírica de sistemas de dominação racional-legal em sua forma pura. Não por acaso, Robert K. Merton e Joseph Ben-David são os principais continuadores de Weber na área de estudos sobre a ciência.
} 
tecnológico existem há milhares deanos, como mostram os estudosdeN eedham sobre a C hina (N eedham, 1947), mas é no 0 cidente que a atividade científica adquiriu uma organização própria, com cultura eval ores específicos, como parte deum processo mais amplo de racionalização e diferenciação institucional. Este processo mais amplo incluiu o desenvolvimento da indústria, do comércio, das instituições nacionais, da ordem jurídica, das universidades e das corporações profissionaise de ofício, eéa coexistência einter-relacionamento destes diferentes componentes que caracterizam e explicam o desenvolvimento econômico e institucional das sociedadesmodernas.

Estaidéiaclássica da sociologia weberianatem sido retomada, recentemente, peloseconomistas que seinteressam pela questão da "inovação", entendida como conceito mais amplo do que o de "ciência e tecnologia" ou "pesquisa e desenvolvimento". ${ }^{19}$ Por um lado, énecessário queexistam instituições depesquisa independentes e de cunho acadêmico, onde os pesquisadores tenham liberdade de explorar diversos caminhos e trabalhar na fronteira do conhecimento, sem precisar estar todo o tempo considerando os custose os ben efíciosmais ou menos imediatos de seu trabalho. Por outro, é necessário que exista, na sociedade, "compradores" significativos dos resultados da pesquisa. N os Estados U nidos, queexperimentaram um grande desenvolvimento da pesquisa na segunda metade do século XX, o mundo acadêmico da pesquisa se organizou sobretudo nas universidades, enquanto queo grandecomprador foi o setor militar, engajado na guerra fria. Entre os dois, a pesquisa mais complexa se localizou em grandes laboratóriosnacionais, como 0 ak Ridgee Lawrence Livermore, associadosagrandes universidades. O utro grande comprador foi o setor de saúde, com os $\mathrm{N}$ ational Institutes of $\mathrm{H}$ ealth desempenhando um papel similar ao doslaboratóriosnacionais. Entre estes dois pólos aparentemente tão diferentes foram criadas muitas outras instituições deciência etecnologia, como os institutos dedicadosao levantamento e processamento deinformações, metrologia, registro de patentes, etantos outros.

Comparado a estes grandes financiadores, produtores e compradores institucionais, é possível argumentar que, nosEstadosU nidos, da mesma forma que na Grã-Bretanha e na França, o setor privado teve um papel menor até

\footnotetext{
${ }^{19}$ A literatura internacional sobre sistemas de inovação é muito extensa, sobretudo entre economistas que se dedicam ao tema da tecnologia. Para uma conceitualização abrangente, ver Niosi et al. (1993). Ver também Archibugi e Michie (1997); Dosi, Teece e Chytry (1998); Branscomb e Keller (1998); De la Mothe e Paquet (2000); Mowery e Rosenberg (1998).
} 
recentemente; e partemuito significativa da pesqui sa realizada pelo setor privado tinha como cliente cativo, ou principal, o setor público (como foi o caso, entre outros, daindústria aeronáutica), efoi deste complexo industrial-tecnológicomilitar que saíram os principais recursos para a ciência básica. ${ }^{20}$

0 fim da guerra fria e a ascensão da nova economia, fortemente dependente de conhecimentos científicos etecnológicos, pareciam indicar que o setor empresarial se transformaria no grande comprador e financiador da pesquisa, dentro deuma lógica de custo-benefício maisestrita, deixando menos lugar para a pesquisa desinteressada e de longo prazo (Branscomb, 1995). $\mathrm{N}$ a realidade, nos Estados U nidos pel o menos, a estratégia da "guerra nas estrelas", somada às tensões criadas a partir do 11 de setembro de2001, indicam que os militares continuarão a ser, por muito tempo ainda, um financiador eestimulador importante das pesquisas tecnológicas. ${ }^{21}$

A "penetração do modo industrial na produção do conhecimento", deque fala Fuller, pode ser entendida pelo menos de três maneiras, que ocorrem de formamaisou menossimultânea. A primeiraéamudança deescalaedosprocessos detrabalho. N as ciênciasnaturais, são conhecidosos exemplos dafísica departículas e da astrofísica, em que grande parte do trabalho é feito pela utilização de equipamentos de alta complexidade, coordenando milhares de pessoas. O utras áreas, como a meteorologia, a oceanografia easgeociências, dependem detrabal hos permanentes e de grande escala de obtenção e processamento de dados, e sua interpretação através de modelos formalizados e prédefinidos. $\mathrm{N}$ as ciências biológicas, o seqüenciamento do código genético das espécies é feito de forma mecanizadaesistemática, por equipes demilhares depessoas. ${ }^{22} \mathrm{~N}$ asciênciassociais, as formas artesanais de coleta eprocessamento de dados estão sendo substituídas, cada vez mais, por levantamentos estatísticos feitos por instituições multilaterais, como o Banco M undial, as N ações Unidas e a OCDE, por agências governamentais, ou por firmas especializadas. Em todas estasatividades, astarefas

\footnotetext{
${ }^{20}$ Para a interdependência entre a ciência acadêmica norte-americana e a guerra fria, ver Menand (2001); Graham e Diamond (1997); Bender (1998).

${ }^{21}$ Ainda não está claro, no entanto, quanto que o setor militar é hoje auto-suficiente em termos tecnológicos, e quanto depende de pesquisas feitas nos setor privado. Em um survey recente sobre a indústria militar, que mobiliza cerca de 200 bilhões de dólares anualmente, a revista The Economist diz que "fifty years ago, high spending on defence fuelled by the cold war produced many technical breakthroughs, from semi-conductors to nuclear power, which brought great benefits to the rest of the world. Now, if anything, the flow seems to be reversed, with the defence industry looking to rapidly advancing technology in commercial industries such as electronics and computer software to keep weapons up to date." The Economist, 2002, p. 4.

${ }^{22}$ Ver o Projeto do Genoma Humano, Hilgartner (1995).
} 
de coordenação e controle do trabalho de grandes equipes são essenciais, e as doutrinas e concepções organizacionais que eram típicas da atividade industrial passaram também a ser utilizadas no mundo da pesquisa.

A segunda maneira se refere às transformações que ocorrem no nível dos valores. Instituições como os sistemas deper review; as atribuições de prioridade e prestígio queidentificam erecompensam os cientistas mais bem-sucedidos; os prêmios científicos; os comitês editoriais das revistas acadêmicas; todos estes mecanismos de estimular a excelência do trabalho acadêmico ainda persistem e estão baseadosnos val ores descritos por $M$ erton, por mais contaminadosqueeles possam estar por outros comportamentos e atitudes. 0 que é novo é o reconhecimento deque, a estessistemastradicionais de reconhecimento do mérito e da qualidade do trabalho científico, começam a ser agregados outros valores, quevão da utilidadeindustrial ecomercial à "correção política" ou ao exercício de poder. Esta transformação e mistura de valores faz parte de um processo muito mais amplo dequestionamento dos supostos do iluminismo eda modernidade, e têm como resultado introduzir altos graus de conflito, expectativas eincerteza no mundo da ciência, aonde, pelo menos aparentemente, parecia reinar a ordem ea racionalidade da culturacientífica. ${ }^{23}$

A terceira, finalmente, serefereà questão da "ciência proprietária", ou, dito deforma mais adequada, "apropriada", ou seja, à questão do segredo edos direitos privados sobre as descobertas científicas. $\mathrm{N}$ ão há nada novo na noção de que 0 conhecimento científico podeter grande valor econômico emilitar, equestões de segredo epatenteamento deconhecimentos científicosetecnológicos são antigas. Ainda assim, a noção dequea propriedadeintelectual seestabelecepela prioridade depublicação das descobertas, enão pela sua guarda, semprepreval eceu nosmeios acadêmicos, tornando problemática a convivência com os valores e as normas vigentes nos meios empresariais, governamentaise, sobretudo, militares. 0 que parece estar ocorrendo hojeé uma exacerbação da preocupação com o tema da apropriação dosconhecimentos, que seexplicapelos custos crescentes da atividade de pesquisa, pelos seus benefícios comerciais cada vez mais evidentes, e pelo debilitamento dosvaloresmaisclássicos da ciência acadêmica.

\footnotetext{
${ }^{23}$ A dita "teoria forte" da sociologia da ciência, ao chamar a atenção para a natureza contingente e socialmente condicionada da atividade científica nas ciências naturais, tem sua parcela de responsabilidade nesta quebra dos valores tradicionais dos meios científicos, provocando fortes reações, que se consubstanciaram nas chamadas "science wars". Ver a respeito Sokal e Bricmont (1997); Segerstråle (2000); Ashman e Baringer (2000).
} 
Por uma ou outra razão, o fato é que a ciência contemporânea tendea ser cada vez mais "proprietária", ou apropriada, tanto por parte dos pesquisadores, financiadores efirmas que apóiam o trabal ho de pesquisa e desenvolvimento, como por parte de populações cujas tradições e áreas em que vivem foram exploradas para a pesquisa de elementos de potencial utilidade ou valor de mercado, eque hoje demandam retribuição. Além disto, a ampla liberdade que tinham cientistas, tecnólogos eseusfinanciadores de fazer seus estudos edecidir o que deve ou não ser utilizado se reduziu enormemente. $H$ oje, agências reguladoras, governos e movimentos de opinião pública colocam as questões derisco, queanteseram administradas pelos cientistasetecnólogos, em patamares até recentemente desconhecidos, e segundo uma lógica não redutível às estimativas estatísticas usuais. ${ }^{24} \mathrm{U}$ m exemplo disto é a questão dos alimentos geneticamente modificados, cuja pesquisa e utilização, apoiada por muitos cientistas, encontra resistências e oposições extremamente fortes por parte da opinião pública de muitos países, que também se organiza, contrata pesquisadores e desenvolve sua própria expertise, tornando impossível reduzir as controvérsias a uma oposição simples entre "ciência" de um lado e "opinião", "ideologia", ou que nome se queira dar, do outro.

\section{Os diferentes modelos de organização da atividade de pesquisa}

Todas estas transformações não significam que a pesquisa esteja deixando as universidades e institutos públicos e se transferindo para o setor industrial. $M$ as a pesquisa acadêmica é hoje muito mais aberta e porosa aos valores e formatos organizacionais próprios do mundo empresarial do que no passado, implantando procedimentos gerenciais baseados na divisão do trabal ho e em metas de desempenho, estabelecendo escritórios para a comercialização de tecnologias, desenvolvendo joint-ventures com o setor privado, tudo isto marcando o esmaecimento dasfronteiras ebarreiras que antes pareciam separar o mundo da academia do mundo da vida prática e dos negócios (Godin e

\footnotetext{
${ }^{24}$ Ver a respeito, por exemplo, Douglas e Wildavsky (1982); e Branscomb e Auerswald (2001).
} 
Gingras, 2000; M cM illan G.S., N arin F. e D eeds D.L., 2000; Teichler e Sadlak, 2000; Sadlak e Altbach, 1997; Vessuri, 1995).

Q uando, no Brasil, falamos de ciência e tecnologia, pensamos muitas vezes em um certo modelo que se aplicariaa todo o conjunto de atividades que se exercem sob estetítulo, do ensino de pós-graduação ao desenvolvimento da inovação na indústria, passando pela elaboração e análise de estatísticas públicas. Este modelo é o da ciência acadêmica, com seus mecanismos de revisão por pares, publicações deartigosem revistas científicas, etc. O utras vezes, éo modelo das aplicações para o desenvolvimento econômico, que vem acompanhado dos conceitos e questões rel acionadas com eficácia, custo benefício, prioridades, e assim por diante. $\mathrm{N}$ a realidade, além destes dois modelos, existe um terceiro, que não faz parte das interpretações ou preferências que possamos ter sobre a natureza do trabal ho científico etecnológico, mastem uma presença dominante em quase todos os setores daadministração pública - éo modelo da organização pública burocrática, com suas carreiras funcionais eestruturas burocráticas rígidas, imprevisibilidade orçamentária e baixa correlação entre desempenho, recompensas e recursos. $N$ ão estaria longe da verdade descrever o sistema de ciência e tecnologia em termos destes três modelos, na forma de organizações burocráticas que são impelidas a assumir um dos dois model os deorganização institucional, 0 acadêmico ou 0 aplicado, a partir de estruturas organizacionais efuncionais que não são adequadas nem para um, nem para outro formato. É uma realidade que acompanha nossas instituições científicas desde muito tempo, ${ }^{25}$ e que se tornou ainda mais acentuada a partir do enrijecimento do serviço público estabelecido pela Constituição de 1988.

\section{A necessidade de aprofundar a reorganização da atividade de pesquisa no Brasil}

0 exameda literatura internacional, o estudo mais aprofundado dealguns setores em que 0 interesse público tem se manifestado com mais nitidez em relação à pesquisa, e a própria observação mais ampla do desenvolvimento da

\footnotetext{
${ }^{25}$ Schwartzman (1981b). A estes três modelos, Elzinga e Jamison (1995) acrescentam um quarto, pouco comum em nosso meio, que é o modelo do centro de pesquisa empresarial, típico do setor privado.
} 
pesquisa científica tecnológica nos últimosanos Schwartzman, Bertero, Krieger et al., 1995), sugerem queo Brasil precisa aprofundar muito maisa reorganização de seu sistema de ciência e tecnologia, para torná-lo compatível com as transformações que vêm ocorrendo em todo mundo e, na prática, no próprio País. 0 nó do problema está em que a organização do sistema de ciência e tecnologia, ea própria cultura institucional da comunidade científica, não vêm acompanhando deforma suficiente estas transformações.

0 Brasil tem tradições importantes de investimentos em ciência e tecnologia aplicada no setor público, seja através do M inistério da Ciência e Tecnologia e suas agências, seja através de outros M inistérios, como os da Saúde, Educação, Trabalho, M eio Ambiente, Planejamento e Agricultura. O s temas são os mais variados - o meio ambiente em seus diferentes aspectos, clima, transportes, energia, comunicações, segurança, saneamento, saúde pública, planejamento urbano, desigualdade social, dívida pública, inflação, pobreza, educação. Vários destestemas são denatureza econômica e social, evários outros têm um forte componente de ciências naturais e biológicas. Existem exemplos importantes de sucesso, sobretudo na área da pesquisa agrícola, ${ }^{26}$ mas também na área de pesquisas de fármacos, associada ao programa de atendimento à população de baixa renda portadora deH IV. N osúltimos anos tem havido um esforço importante para responder de forma adequada aos desafios impostos pelo papel crescenteda ciência etecnologia nanova ordem mundial. Esteesforço tem consistido em três linhas de investimentos: na formação de recursos humanos, através de um amplo programa de bol sas de estudo e de pesquisas; do aumento de recursos para a área, ${ }^{27}$ marcados recentemente pela criação de um conjunto de fundos setoriais, que se espera possam fazer dobrar os investimentos brasilei ros em ciência e tecnologia em poucos anos; ena rápida capacitação tecnológica em algumas áreas de ponta, como nos projetos do

\footnotetext{
${ }^{26}$ Para uma visão ampla dos impactos do aumento de produtividade da agricultura brasileira na economia e na sociedade, ver Bonelli (2001).

${ }^{27}$ É muito difícil comparar os dispêndios públicos em ciência e tecnologia através do tempo, no Brasil, por causa das mudanças de conceitos e definições, assim como do impacto da inflação. $O$ entendimento geral é que houve um esforço de gastos importante no governo Geisel, e outro momento de crescimento no governo José Sarney, corroído poucos anos depois pela crise inflacionária. Na década dos anos 1990, segundo o Livro Verde, o gasto, "após ter-se elevado entre 1993 e 1996, voltou a reduzir-se em 1997 e 1998, mantendo-se praticamente estabilizado em 1999, com previsão de recuperação em 2001. A entrada em vigor dos fundos setoriais permite projetar uma trajetória ascendente para os próximos anos. Espera-se que, com essa nova fonte de recursos, os gastos públicos federais em C\&T atinjam um novo patamar e deixem de apresentar a instabilidade que os caracterizou no passado". Brasil, Ministério da Ciência e Tecnologia, Silva, e Melo, 2001, cap. 1, p.32.
} 
Laboratório de Luz Síncroton e o Projeto G enoma, com o trabal ho pioneiro de seqüenciamento da Xilella Fastidiosa. ${ }^{28}$ Ao lado destes desenvolvimentos, têm havido movimentos no sentido de criar vínculos mais estreitos entre a ciência acadêmicaeo setor empresarial privado, sobretudo nacional. ${ }^{29}$

\section{Os novos formatos institucionais}

$N$ este quadro geral, pesquisadores e governantes têm feito uso de imaginação e criatividadee estabelecido uma série de estruturas esistemas que escapam às formalidades do serviço público, assim como à rigidez dos modelos acadêmicos e de ciência aplicada, buscando se aproximar das estruturas complexas e mistas que são mais típicas das formas mais atuais de produção do conhecimento. Existe um duplo movimento no sentido de maior abertura e contato da área científica com a área empresarial, e também com as organizações e movimentos sociais. Assim, na área de medicamentos, Far$M$ anguinhos monta um sistema de gerenciamento de tipo empresarial; nas pesquisas sobre emprego e trabalho, a rede U nitrabalho se estrutura como organização não-governamental de direito privado; e os centros de pesquisana área ambiental buscam novasformas de controlee apropriação da propriedade intelectual dos produtos de suas pesquisas, e de acordos de cooperação internacional com instituições públicas e privadas. Ao mesmo tempo, organizações não-governamentais na área ambiental, do trabal ho eda educação participam ativamente das discussões, da definição e muitas vezes da própria execução de pesquisas que podem influenciar as decisões públicas em suasárea deinteresse. Seria proveitoso poder dimensionar quanto dos recursos disponíveis para a pesquisa no Brasil podem ser utilizados desta forma, e quantos, ao contrário, estão sujeitos a amarrações e limitações de vários tipos.

\footnotetext{
${ }^{28}$ O Projeto Genoma não teve o objetivo de tratar de um problema agrícola enquanto tal, mas de criar competência em genômica seqüencial, para em seguida desenvolver competência em genômica estrutural e assim por diante, capacitando o País para, mais adiante, participar de forma mais efetiva nas áreas mais avançadas de pesquisa e aplicações em biotecnologia. Um aspecto importante desta pesquisa foi sua organização em rede, através da Organization of Nucleotide Sequencing and Analysis (ONSA), criada pela Fundação de Amparo à Pesquisa de São Paulo (FAPESP).

${ }^{29}$ A FAPESP, que até recentemente operava quase que exclusivamente nos moldes da ciência acadêmica, nos últimos anos têm feito grandes investimentos em projetos temáticos e orientados para resultados econômicos e práticos. Ver a respeito Landi, (1998) e Perez (2000).
} 
Estas inovações ad hoc, ao mesmo tempo em queabrem novoscaminhos, não deixam de trazer seus próprios problemas, alguns de natureza mais questionável, outros reais. Em princípio, não haveria porquese preocupar com as diferenças de recursos e oportunidades geradas pela competição entre pesquisadores esuas instituiç̧ões, na medida em que elas reflitam as diferenças em importância, reconhecimento e prioridade que a sociedade atribui às diferentes áreas e grupos de pesquisa. Também não parece correto interpretar estes mecanismos como uma forma de "privatização" da pesquisa, já que se trata, tão-somente, deencontrar formas mais eficientes de gerenciar os recursos públicos, atendendo também ao interesse público. A ciência ea tecnologia não funcionam de forma adequada em ambientes homogêneos e burocráticos, ea natureza pública deste setor está dada, fundamentalmente, por seus benefícios sociais, que justificam o investimento público, e não pelo seu formato institucional. São mais pertinentes, por outro lado, as preocupações com a eventual perda de qualidadee relevância da pesquisa, que podeocorrer quando os padrões de referência deixam de existir, e quando recursos são distribuídos por critérios meramentepolíticosou ideológicos. Resolver a questão institucional écrucial para permitir quea ciência brasileira aumente deforma mais rápida seu desempenho e sua qualidade, tanto do ponto de vista acadêmico como educacional eaplicado. Infelizmente, as expectativas de que as instituições de pesquisa federais viessem a se beneficiar de uma reforma administrativa mais aprofundada se frustraram nos últimos anos, e será necessário aguardar agora umanova oportunidade. ${ }^{30}$

0 granderisco que existenesta passagem do modelo tradicional erígido da ciência acadêmica para o mundo das aplicações e da efetividadeéqueo lado acadêmico se perca no caminho, sem queo lado dos resultados edas aplicações chegue a se materializar. 0 uso de conhecimentos resultantes de estudos e pesquisas paraa implementação de políticas públicas éaindaincipienteno Brasil, evaria muito deárea paraárea. Em um extremo, como a área da saúde pública e dos medicamentos, existe um relacionamento já estabelecido, que começa com os trabal hos de preven ção das doenças tropicais no início do século, que deram origem ao que é hoje a Fundação 0 swaldo C ruz (Stepan, 1976). 0

\footnotetext{
${ }^{30}$ Schwartzman (1994b). Para uma análise mais ampla, Salles Filho (2000).
} 
mesmo ocorrena área da agricultura, aonde se destacam, entretantos exemplos, as pesquisas pioneiras de $J$ ohana $D$ öbereiner sobre os processos de fixação do nitrogênio por bactérias em plantas, que permitiram a recuperação da região do cerrado para a agricultura (Chagas Filho, 1998). N a área do meio ambiente, no entanto, este uso quase não existe, apesar de sua importância óbvia, o que se explica, provavelmente, pela institucionalização ainda incipiente do próprio M inistério da área. N a educação, apesar da história antiga do IN EP, é só nos últimos anos que ele começa a se desenvolver efetivamente como um centro governamental deprodução deinformaçõese geração deestudos, mas ainda não dispõe dequadrospróprios de pesquisa eanálise, nem tampouco desistemaformal de contratação euso de pesquisas contratadas com a comunidade depesquisa.

A pesar disto, como vimos, são as áreas aplicadas que absorvem a maior parte dos recursos de pesquisa, logo após os investimentos em formação de recursos humanos. Assim, do dispêndio de 2.8 bilhões de reais listados nos programas governamentais do ano 2000, 908 milhões foram para recursos humanos (bolsas do CN Pq e financiamento da pós-graduação) e um bilhão para tecnologia industrial, programas militares etecnologias da informação. A área social, queéequivocadamenteconsideradacomo recebendo poucos recursos, contou no ano 2000 com cerca de 450 milhões de reais para o Censo do Ano $2000,{ }^{31}$ e gasta volumes consideráveis de recursos através de programas e instituições como o FAT, IN EP, IBG E, IPEA, SEADE, e vários outros.

Se isto é assim, estamos diante de um paradoxo importante: o Brasil gasta a mai or parte de seus recursos de pesquisa em atividades aplicadas, mas os resultados não são utilizadosnem aparecem como deveriam aparecer. Existem, naturalmente, importantes esignificativas exceções a esta regra, que, no entanto, parece predominar. Em parte, esta situação se vê refletida nas anedotas que correm há anos entreos pesquisadores da área biomédica, que dizem quefazem "pesquisa pura no bicho aplicado", ou que, no Brasil, "existem mais pessoas vivendo do quemorrendo deC hagas". 0 queestas anedotas revelam éa existência deuma estratégia, entrepesquisadores deáreas básicas, deapresentar seus projetos como se fossem aplicados, para assim obterem mais verbas. Como a pesquisa

\footnotetext{
${ }^{31}$ O custo do censo, no entanto, é bem maior, se considerarmos os trabalhos preparatórios que começam vários anos antes, e as análises que se desenvolvem nos anos seguintes ao recenseamento propriamente dito. Curiosamente, o Ministério da Ciência e Tecnologia, em suas compilações sobre os gastos brasileiros em ciência e tecnologia, não inclui os gastos do IBGE na área de pesquisa socioeconômica e cartografia, nem os do IPEA, na área de estudos sociais e econômicos.
} 
em geral é de boa qualidade e potencialmente relevante, esta estratégia é geralmente considerada como uma contrafação benigna, por uma boa causa.

Existe não obstante outro cenário, em que a pesquisa se realiza com objetivos aplicados, mas seus resultados nunca se aplicam. Esta étambém uma situação conhecida, que recebe a denominação de "pesquisa de prateleira": 0 trabalho avança até a elaboração de um protótipo, por exemplo, ou de um projeto piloto, masnunca chega a setransformar em um produto comercializável, ou em um procedimento operacional e prático, seja no setor privado, seja no setor público. Existem muitas razões possíveis para esta situação, sendo a mais comum a situação em que, apesar da intenção dos pesquisadores edas agências de financiamento em produzir resultados aplicáveis e rentáveis, não existem compradores ou usuários efetivos para estes resultados. Um exemplo típico desta situação é quando uma agência governamental realiza um programa de tipo "induzido", em que pesquisadores ou centros de pesquisa são chamados a apresentar projetos para tratar ou resolver certos tipos de problema. Independentemente da pertinência dos editais e da qualidade técnica dos trabalhos, estes programas geralmente não incluem, na outra ponta, as empresas ou instituições que seriam os usuários das pesquisas. A expectativa, que quase nunca se materializa, équeum bom resultado de pesquisa ou desenvolvimento tecnológico permitiria identificar, em uma segunda etapa, setores ou grupos interessados em seu uso. $\mathrm{N}$ a tentativa de superar este problema, a década de 1990 foi marcada por uma variedade de programas elinhas de financiamento da FAPESP, FIN EP e M inistério da Ciência eTecnologia que condicionam 0 recurso à efetiva existência deparcerias entre pesquisadores eusuários da pesquisa.

$\mathrm{N}$ ão existe nenhuma avaliação sistemática, no entanto, dos resultados destas políticas, e muitas razões para temer que ele não seja muito positivo. A primeira razão é que nem sempre estes usuários existem, ou estão preparados ou interessados em fazer uso dos resultados. $\mathrm{N}$ a área ambiental, por exemplo, estudos sobre o impacto da ocupação desorganizada da terra em regiões de floresta, por mel horesque sejam, não levam necessariamentea políticas públicas de contenção ou redirecionamento dos assentamentos. A segunda é que, na ausência de um comprador claramentedefinido, os produtos da pesquisa muitas vezes não têm as características necessárias para que possam ser defato utilizados. Assim, na área de fármacos existe uma grande distância entre a descoberta de 
um princípio ativo esua transformação em um medicamento com propriedades e efeitos secundários conhecidos, quepermita sua utilização na prática médica. ${ }^{32}$

\section{Os novos procedimentos de avaliação}

0 conceito de "ciência eficaz" adquire sentidos diferentes quando passamos de uma área de conhecimento para outra. $\mathrm{N}$ a visão mais simples, a idéia de eficácia está associada a um produto tecnológico qualquer - um medicamento, uma máquina, um objeto de consumo - que resulta do trabalho de pesquisa. M as é considerada eficaz a pesquisa queleva a decisões de política governamental, ou decisões empresariais - estudos sobre o emprego, por exemplo, que podem gerar mudanças na legislação trabalhista, enas políticas de pessoal das empresas? 0 eventual uso ou impacto de uma pesquisa pode não depender da natureza do trabalho queéfeito, esim das condições do ambiente em que este trabal ho se desenvolve. Um governo interessado em melhorar a educação vai dar mais atenção às pesqui sas educacionais do que um outro que não tem esta preocupação. Áreas depesquisa como as ciências sociais, ou estudos sobremeio ambientee clima, podem ter impactos de médio elongo prazos, ao contribuir para formar opinião, sem quetenham utilização imediata. ${ }^{33}$

Como sejustificaqueo Paísgastetantosrecursosnaformação técnicaecientífica eem projetos aplicados, se o uso efetivo destas competências e conhecimentos, nos seus diversos sentidos, étão limitado? A resposta geral para esta pergunta é queo País precisa, ecada vez mais, de gente qualificada e, neste sentido, tudo 0 que se gasta em pesquisa e recursos humanos ainda épouco, eque os resultados virão com o tempo. A verdadeindiscutível desta resposta não deve impedir, no entanto, que ol hemos criticamente para a manei ra pela qual estes recursos estão

\footnotetext{
${ }^{32}$ Uma inovação importante, neste sentido, tem sido o programa de apoio a pesquisas em políticas públicas da FAPESP, que exige a vinculação entre pesquisadores e usuários de seus trabalhos. Em 2002, "A FAPESP recebeu 226 projetos, dos quais 162 foram pré-selecionados e 61 aprovados. Participam dos trabalhos anunciados 18 instituições de pesquisa, estaduais, federais ou particulares, 28 prefeituras, 26 secretarias de Estado e 7 organizações não-governamentais. Em relação às áreas, predominam os projetos sobre Ambiente (13), seguidos por Educação (10), Saúde e Administração e Gestão (9 cada), Arquivos (4), Trabalho, Emprego e Renda (3), Agricultura e Pecuária, Habiłação, Patrimônio Histórico, Urbanismo e Segurança e Justiça (2) e Economia, Crédito e Taxas, Geração de Empresas e Transporte (1 cada)". http://www.fapesp.br/politica475.htm

${ }^{33}$ Um quadro bastante elaborado das diferentes aplicações e usos das ciências sociais pode ser visto em Brunner e Sunkel (1993). Ver também os trabalhos de Carol Weiss, entre os quais Weiss (1986) e Brooks, Gagnon, Conway et al. 1990.
} 
sendo gastos, perguntando-nos se a forma pela qual nosso sistema de ciência e tecnologia está constituído éa mais adequada e conveniente. 0 setor de ciência e tecnologia, como qualquer outro setor na sociedade, é formado por pessoas que têm interessena obtenção de recursos cada vez maiores para suas atividades e instituições, e buscam os mel hores argumentos possíveis para justificar suas demandas crescentes. Por isto mesmo, éimportantepoder tomar certa distância e examinar se os recursos despendidos estão, de fato, atendendo aos propósitos para os quais el es deveriam se destinar.

Tudo isto leva à necessi dade de repensar os procedimentose mecanismos utilizados pela sociedade para avaliar ejustificar os investimentos em ciênciae tecnologia. O s procedimentos tradicionais utilizados para a ciência acadêmica, o chamado "modo 1", são conhecidos, e continuam importantes: o peer review, o acompanhamento de desempenho através de publicações científicas, etc. Para os que trabalham em universidades, um elemento adicional dejuízo é a quantidade e qualidade dos alunos formados pelas instituições. Para a ciência aplicada, o critério é o uso, e a satisfação do cliente. Como se trata, quase sempre, de atividades complexas e de resultados de longo prazo, a aplicação mecânica destes critérios de avaliação pode produzir resultados equivocados. Por exemplo, grupos emergentes com grande promessa de qualidadenão podem ser comparados, em termos dequantidade de produção, com grupos já estabelecidos; tecnologias incipientes, mas promissoras, não podem ser avaliadas em termos de seus resultados práticos de curto prazo. $M$ as o eventual uso inadequado eirrefletido destes procedimentos de avaliação não justificam que eles sejam postos de lado.

M esmo com suas limitações, estes procedimentos são freqüentemente desconhecidos, ignorados ou consideradosirrelevantes em instituições dominadas por culturas burocráticas, políticas ou empresariais, fazendo com que seja impossível ter uma idéia mais clara e consistente a respeito da efetividade da pesquisa que se desenvolveno País. ${ }^{34} \mathrm{~N}$ ão só faltam mecanismos adequados de avaliação (com al gumas exceções importantes, como, por exemplo, o sistema deacompanhamento dos cursos depós-graduação daCAPES), masas instituições

\footnotetext{
${ }^{34}$ Os dados produzidos pelo Ministério de Ciência e Tecnologia se referem, quase que exclusivamente, à oferta de recursos em ciência e tecnologia - número de pesquisadores, recursos investidos, linhas de pesquisa, doutores formados, etc. A única informação disponível de produtos é a de publicações científicas, que também fazem parte da oferta, e não da produção de bens e serviços, do ponto de vista da sociedade e da economia.
} 
tampouco têm condições detomar decisões que possam alterar de forma mais decisiva suas orientações, práticas de trabal ho euso de recursos.

A avaliação desetores, projetose políticas globais de ciência etecnologia se constitui hoje em uma especialidadetécnica, quetem sido utilizada, sobretudo, pela OCDE, ${ }^{35}$ e precisaria ser mais desenvolvida em nosso meio. A cultura da avaliação, que hoje existe em boa medida em instituições como a FAPESP, 0 C N Pq e o M inistério da Educação, deveria ser estendida para outros setores da administração pública, e especialmente para setores que têm investimentos significativosem áreasquerequerem investimentos em ciência etecnologia, como os de saúde, energia, meio ambiente, trabal ho e segurança.

$M$ as seria ilusório supor que a questão estaria resolvida pela adoção de novos procedimentos técnicos de avaliação, que substituíssem os antigos procedimentos deavaliação por paresqueainda predominam nasmelhoresagências de fomento à pesquisa e educação. U ma característica central do novo contexto da pesquisa científica etecnológicaéqueela éhojedeinteressedegruposesetores sociais muito amplos e variados, que não aceitam mais o domínio do setor por grupos decisórios operando intramuros, por mais competentes, respeitáveis e tecnicamente bem municiadosquesejam. 0 Brasil conhecebem osmecanismos de mobilização de interesses setoriais e corporativos da própria área científica e tecnológica para o controle dos recursos de pesquisa, que se manifestam através dos processos de indicação de representantes de diversos setores em órgãos colegiais, das pressões e demandas de natureza regional e setorial, dos conflitos intraburocráticos pela distribuição derecursos entre diferentesárease projetos. A expectativa é que, na medida em que o setor de ciência e tecnologia cresça em importância, outros setores da sociedade, dasorganizaçõesnão-governamentaisàs grandes corporações, passando por organizações internacionais e pelos partidos políticos, comecem também a querer exercer influência e fazer valer suas preferências epontos devista.

Esta politização da pesquisa pode ter efeitos extremamente negativos, ao impedir o crescimento denovas linhas detrabalho, desviar recursos para regiões, grupose setores de baixa competência, esustentar projetos degrandevisibilidade, mas baixo potencial eimpacto. $M$ as ela podetambém ter um papel extremamente

${ }^{35}$ OECD - Organization for Economic Co-operation and Development (1997); Durand e Giorno (1987). 
positivo, ao orientar recursos para setores de grande interesse social, e garantir a continuidadedosinvestimentose do apoio político para o setor. 0 quefazadiferença entreestas duas possibilidades éa percepção quea sociedade possa ter a respeito da importância do trabalho que se desenvolve nos meios aonde se produz ciência, tecnologia e educação de qualidade, enão o fechamento dos processos de decisão em grupos tecnocráticos de uma ou outra natureza. A ciência e a tecnologia se desenvolvem, e jogam um papel significativo na sociedade, quando a sociedade entendeeconfia em sua importância, eestá disposta a pagar por isto. A existência desteentendimento econfiançadepende, em grandeparte, dosprópriospesquisadores e tecnólogos, que têm a responsabilidade de ouvir e dialogar com a sociedade, aprendendo com ela, emostrando a contribuição quetêm adar. N ão éum caminho fácil, mas pareceser o único possível, etambém o maisgratificante, sebem-sucedido.

\section{Conclusão}

A análise das novas formas de organização daatividade científica no mundo atual, com a redução ou o desaparecimento das barreiras entre ciência pura e ciência aplicada, em conjunção com a análise do papel central do setor público não somenteno financiamento, mas sobretudo no uso dos resultados da pesquisa científica, levam à necessidade de reorganizar de maneira bastante profunda 0 sistema de pesquisa científica no País. 0 sentido geral desta reorganização deveria ser o deabrir asinstituições, cada vez mais, para a sociedademaisampla, tornandoas mais flexíveis, mais capazes de estabelecer parcerias com diferentes setores da sociedade, e sujeitas a novos procedimentos de avaliação, que tomem em conta não somentea excelência acadêmica dos trabal hos, ou suas aplicações, mas possam combinar ambos os critérios. Esta reorganização deveria afetar também as próprias instituições de fomento à pesquisa científica, que deveriam poder trabal har de forma mais integrada com os diversos setores da sociedade brasileira que têm necessidade e fazem uso dos resultados da pesquisa cientifica e tecnológica. A criação recente dosfundos setoriais não deve ser vista como a simples criação de um novo mecanismo financeiro para dar continuidadeàs práticas de sempre, mas como o embrião deum novo formato derelacionamento entreo interesse público ea pesquisa científica, que precisaria ser melhor explorado eaprofundado. 


\section{Bibliografia}

Archibugi, D.; Michie, J., Technology, globalization and economic performance. Cambridge England, N ew York: C ambridge U niversity Press, 1997.

Ashman, K. M.; Baringer, P. S., After the science wars. New York: Routledge, 2000.

Ben-D avid, J., The scientists role in society: a comparative study. Englewood Cliffs, N .J.: Prentice H all, 1971.

Bender, T., "Politics, intellect, and the American university, 1945-1995". In Bender, T.; Schorske, C. E., American academic culture in tranformation - fifty years, four disciplines. Princeton, N .J: Princeton University Press, p. 17-54, 1998.

Bonelli, R., Impactos econômicos e sociais de longo prazo da expansão agropecuária no Brasil: revolução invisível e indusão social. Braślia: Embrapa. Seminário I mpactos da mudança tecnológica do setor agropecuário na economia brasileira, 2001.

Botelho, A.; Schwartzman, S., "Growing pains: Brazilian scientists and their shifting roles". In Gaillard, J.; Krishna, V. V.; Waast, R., Scientific communities in the developing world. N ew D elhi, Thousand $O$ aks, $C$ alif: Sage Publications, p. 336-353, 1997.

Branscomb, L. M., "United States science and technology policy: issues for the nineties". In Schwartzman, S.; Bertero, C. O .; Krieger, E. M. et. al. (eds). Science and technology in Brazil: a new policy for a global world, vol. 1, Rio de Janeiro: Editora da Fundação G etúlio Vargas, 1995.

Auerswald, P. E., Taking technical risks. how innovators, managers, and investors manage risk in high-tech innovations, Cambridge, M ass: M IT Press, 2001.

; Keller, J., Investing in innovation - creating a research and innovation policy that works. Cambridge, M ass: M IT Press, 1998.

; Kodama, F., Japanese innovation strategies - technical support for business visions. C ambridge, $\mathrm{M}$ ass: $\mathrm{C}$ enter for Scienceand International Affairs, $\mathrm{H}$ arvard University, CSIA occasional paper n. 10, 1993.

Brasil. M inistério da Ciência eTecnologia. Silva, C. G.; M elo, L. C. P. (orgs.), Ciência, tecnologia e inovação - desafio para a sociedade brasileira - Livro Verde. Braślia: M inistério da Ciência e Tecnologia/Academia Brasileira de Letras, 2001. 
Brasil, M inistério do Planejamento. D espesa por programa, exercício de 1995 a 2000. http://www.planejamento.gov.br/orcamento/conteudo/estatistica/quadros/ estatistica_1995_2001/dados_serie_historica/despesas_programa/ exercicio_19̄95a2000.htm (acessado em 2001).

Brooks, S.; Gagnon, A. G.; Conway, T. et. al., Social scientists, policy and the state. New York: Praeger Publishers, 1990.

Brunner, J. J.; Sunkel, G ., Conocimiento, sociedad y política. Santiago, Chile: Facultad Latinoamericana de Ciencias Sociales (FLACSO), 1993.

Chagas Filho, C. Entrevista de Johana D öbereiner. In Sociedade Brasileira Para 0 Progresso da Ciência Cientistas do Brasil - vários depoimentos. São Paulo: SBPC, p. 77-85, 1998.

Coelho, E. C., As Profissões Imperiais: Advocacia, M edicina e Engenharia no Rio de Janeiro, 1822-1930. Rio de Janeiro: Editora Record, 1999.

David, P. A., Behind the diffusion curve - theoretical and applied contributions to the microeconomics of technology adoption. Boulder, C olorado: Westview Press, 1997.

De La M othe, J.; Paquet, G ., Information, innovation, and impacts. N orwell, M ass: Kluwer Academic. Economics of science, technology, and innovation, 2000.

D osi, G.; Teece, D . J.; Chytry, J., Technology, organization and competitiveness perspectives on industrial and corporate change. Oxford: Oxford University Press, 1998.

D ouglas, M .; Wildavsky, A. B., Risk and culture an essay on the sel ection of technical and environmental dangers. Berkeley: University of California Press, 1982.

D urand, M .; G iorno, C., "Indicators of international competitiveness: conceptual aspects and evaluation". OECD Economic Studies, v. 9, n. Autumn, p.147-82, 1987.

The Economist. "A survey of the defence industry". The Economist, $n$. June 20, 2002.

Edge, D.; "Reinventing the wheel". In Jasanoff, S. M. G.; Petersen, J. C.; Pinch, T., Handbook of science and technology studies. Thousand $O$ aks, Calif: Sage Publications, 3-24, 1995.

Elzinga, A.; Jamison, A., "Changing policy agendas in science and technology", ch. 25. In Jasanoff, S. M. G. E.; Petersen, J. C.; Pinch, T., H andbook of science and technology studies. Thousand $\mathrm{O}$ aks, Calif: Sage Publications, $\mathrm{p}$. 572-597, 1995. 
Fuller, S.; "Is there life for sociological theory after the sociology of Sociology?", The Journal of the British Sociological Association, v. 29, n.1 (Feb), p.159, 1995.

Gibbons, M.; Trow, M.; Scott, P. et. al. The new production of knowledge - the dynamics of science and research in contemporary societies London, Thousand O aks, California: Sage Publications, 1994.

Godin, B. E Gingras, Y., "The place of universities in the system of knowledge production." Research Policy, v. 29, n.2, p. 273-78. 2000.

Graham, H . D .; Diamond, N ., The rise of American research universities elites and challenges in the postwar era. Johns H okpins University Press, 1997.

Graham, L. R., What have we learned about science and technology from the Russian experience? Stanford, Calif: Stanford University Press, 1998.

H ilgartner, S., "The H uman Genome Project". In Jasanoff, S. M . G. E.; Petersen, J. C. e Pinch, T., H andbook of science and technology studies. Thousand $O$ aks, California: Sage Publications, p. 302-315, 1995.

Joravsky, D., The Lysenko affair, Cambridge, M ass: H arvard University Press, Russian Research Center studies 61, 1970.

K rieger, E.; Galembeck, F., "A capacitação brasileira para a pesquisa". In Schwartzman, S.; Bertero, C. 0 .; K rieger, E. M . et. al. (eds). Ciência etecnologia no Brasil (vol. 3): A capacitação brasileira para a pesquisa científica e tecnológica. Rio de Janeiro: Editora da Fundação G etúlio Vargas,1-18, 1996.

Landi, F. R. (ed.), Vigor e inovação na pesquisa brasileira - resultados de projetos temáticos em São Paulo. São Paulo: FAPESP, 1998.

Latour, B. We have never been modern. C ambridge, M ass: H arvard U niversity Press, 1993.

M ariani, M. C., "Educação e Ciências Sociais: 0 Instituto N acional de Estudos ePesquisas Educacionais". In Schwartzman, S. (org.), U niversi dades einstitui ções científicas no Rio de Janeiro. Brasília: CN Pq, Coordenação Editorial, p. 167195, 1982.

M cmillan G.S.; N arin F. ; D eeds D.L., "An analysis of the critical role of public science in innovation: the case of biotechnology". Research Policy, v. 29, n.1, p. 1-8. 2000.

M enand, L., "College: the end of the golden age". The N ew York Review of Books, n. 0 ctober 18, p. 44-47. 2001. 
M erton, R. K., The sociology of science - theoretical and empirical investigations. Chicago: University of Chicago Press, 1973.

M owery, D. C.; Rosenberg, N., Paths of innovation technological change in 20th century America. Cambridge, UK, N ew York: C ambridge University Press, 1998.

N eedham, J., Science and society in ancient China. London: Watts, Conway memorial lecture, 1947.

Niosi, J.; Saviotti, P.; Bellon, B. et. al., "N ational systems of innovation: in search of a workable concept". Technology in Society, v. 15, p. 207-27, 1993.

Organisation for Economic Co-operation and D evelopment. Policy evaluation in innovation and technology: towards best practices. Paris, Washington: OECD, OECD proceedings, 1997.

Perez, J. F.; "Pesquisa e ousadia”. Folha de São Paulo, Caderno Tendência/D ebates. 2000.

Sadlak, J.; Altbach, P. G., Higher education research at the turn of the new century structures, issues, and trends. Paris, N ew York: U N ESC O . Garland Publications, 1997.

Salles Filho, S. (coord.). Ciência, tecnologia e inovação - A reorganização da pesquisa pública no Brasil. Campinas: Editora Komedi, 2000.

Schwartzman, S., "Ciência, tecnologia, tecnocracia e democracia”. In Schwartzman, S., Ciência, universidade e ideologia: a política do conhecimento. Rio de Janeiro: Zahar Editores, cap. 1, 1981a.

"M odel os de atividade científica". In Schwartzman, S.; Carvalho, A. P. D .; Leite, R. C. et. al., Administração da atividade científica. Braślia: FIN EP/ CN Pq, p. 9-18, 1981b.

"D esempenho das unidades de pesquisa: ponto para as universidades". Revista Brasileira de Tecnologia, v. 16, n.2, p.54-60, 1985.

"Brazil: Scientists and the State - Evolving Models and the 'Great Leap Forward'". In Solingen, E. Scientists and the state domestic structures and the international context. Ann Arbor: University of Michigan Press, p. 171188, 1994a.

"O s Institutos de pesquisa do Governo Federal",1994b. http:// www. airbrasil.org.br/simon/inpesq.htm

"A Força do novo". In Schwartzman, S., A redescoberta da cultura. São Paulo: Edusp - FAPESP, 1997. 
U m espaço para a ciência: a formaçao da comunidade científica no Brasil. Brasília: M inistério de Ciência e Tecnologia, Conselho Nacional de D esenvolvimiento Científico eTecnológico, Centro de Estudos Estratégicos, 2001.

Balbachevsky, E., The academic profession in Brazil. In Altbach, P. G. (ed.). The international academic profession portraits of fourteen countries. Princeton, N .J: Carnegie Foundation for the Advancement of Teaching, p. 231-280, 1996.

Bertero, C. O.; Krieger, E. M. et. al. (eds.). Ciência e tecnologia no Brasil: uma nova política para um mundo global. Vol 2:. política industrial, mercado de trabalho e institui ções de apoio. Rio de J aneiro: Editora da Fundação Getulio Vargas, 1995.

Segerstråle, U . C . O ., Beyond the science wars the missing discourse about science and society. Albany: State University of N ew York Press, 2000. SU N Y series in science, technology, and society.

Sokal, A. D.; Bricmont, J., Impostures intellectuelles. Paris: O. Jacob, 1997.

Stepan, N ., Gênese e evolução da ciência brasileira: O swaldo Cruz e a política de investigação científica e médica. Rio de Janeiro: Artenova, 1976.

Teichler, U .; Sadlak, J., H igher educati on research its relationship to policy and practice. O xford: Pergamon Press, International Association of Universities, Issues in higher education, 2000.

Todeschini, R. (Representante da CUT no CODEFAT), "O FAT e o CODEFAT nas Políticas Públicas de Emprego e Renda no Brasil", Internet, 2002.

Vessuri, H. M . C., La academia va al mercado relaciones de científicos académicos con clientes externos. C aracas: Fondo Editorial FIN TEC. D istribuido por M onte Avila Editores Latinoamericana, 1995.

Weiss, C. "The many meanings of research utilization". In Bulmer, M ., Social science and social policy. London, Boston: Allen \& Unwin, p. 31-40, 1986. 